\title{
Unbalanced Vibration Response Reduction of Rotor Using Active Magnetic Actuator Based on PD Control
}

\author{
Jianfei Yao, Jiabao Dai and Liang Liu \\ Beijing Key Laboratory of Health Monitoring and Self-recoverying for High-end Mechanical Equipment, Beijing \\ University of Chemical Technology, Beijing, 100029, China. \\ College of Mechanical and Electrical Engineering, Beijing University of Chemical Technology, Beijing, China.
}

\begin{abstract}
(Received 11 May 2018; accepted 31 July 2018)
An active control method based on the proportional-derivative (PD) feedback control strategy using an active magnetic actuator (AMA) is proposed for suppressing rotor vibration caused by rotor unbalance. The control current of the AMA is adjusted according to the real-time displacement of the rotor through the PD feedback algorithm to produce an electromagnetic force to reach the vibration response reduction of the unbalanced rotor. The motion equation of the rotor-bearing AMA system is established and transformed into a state equation for designing a control strategy based on the PD feedback. Finally, the test rig is set up and the verifications of simulation and experiment are carried out. The simulation and experimental results show the effectiveness of the proposed method for the suppression of the rotor unbalance vibration.
\end{abstract}

\section{INTRODUCTION}

Due to the existence of the residual unbalance of the rotor, the rotating machinery will produce vibration and noise during operation, and increase the mechanical wear. As the speed increases, the unbalanced force will show a square-fold surge, so even a small imbalance at high speeds will still produce greater vibration. ${ }^{1}$ It may cause the mechanical instability and even an accident when the vibration is serious. The control of the rotor unbalance vibration is divided into passive control and active control. The passive control structure is simple, which is suitable for simple working conditions and low requirements for stability. ${ }^{2,3}$ Active vibration control can be combined with different control strategies and has higher adaptability and stability. The active magnetic bearing (AMB) uses a controllable electromagnetic force to suspend the rotor and can be used for the active control of the rotor vibration. ${ }^{4-8}$ The AMB is only installed as a rotor active control device that provides electromagnetic force stiffness and damping, not as a static load support, commonly referred to as an active magnetic actuator (AMA). ${ }^{3}$ Compared with other active control devices, an AMA has the advantages of no contact, no lubrication, low energy consumption, and so on. ${ }^{9}$

A lot of research on the active control of rotor vibration using the unique advantages of AMB has been carried out. ${ }^{10-13}$ In the active control field of rotor unbalance vibration, Kumar et al. proposed a 12-pole radial AMB which used AC excitation to counteract the unbalance. ${ }^{14}$ Roy et al. used a viscoelastic control law in AMB to suppress unbalance vibration. ${ }^{15}$ The second-order sliding mode control was applied in Kandil et al. to adjust the AMB system to a wide rotational speed operating range. ${ }^{16}$ Zheng and Feng proposed a rotor unbalance feedforward compensation control based on a new adaptive notch filter. ${ }^{17}$ Cui et al. proposed an adaptive control method for the unbalanced vibration of active-passive hybrid magnetically suspended rotor based on the sliding mode observer combining with the notch filter. ${ }^{18}$ Tang et al. designed an integrated controller to suppress the first and two order bending modes of the rotor. ${ }^{19}$ Mao and Zhu established the dynamics model of an AMB rigid-rotor system and proposed an unbalanced compensator based on a real-time variable-step-polygon-iterativeseeking algorithm for the unbalance coefficients of the rotor to suppress rotor vibration. ${ }^{20}$ Among the methods for reducing rotor vibration, some of them are generally applied at bearing locations, due to the AMB as a static load support, where the vibration is not as severe as at the rotor spanned away from the bearings. ${ }^{21-26}$ However, the reduction of rotor vibration is poor in that the location of the control force is far away from the location of the excitation.

This paper focuses on the reduction of unbalanced rotor vibration by using an AMA in a rotor-bearing system. Firstly, the dynamic equation of the rotor-bearing AMA is established and then transformed into the state space expression. The unbalanced mass is applied to the system, and the unbalanced response of the state equation is obtained by using the ode 45 solver in the MATLAB software. Then, an active control method based on the PD feedback is proposed. The unbalance vibration is decomposed into two orthogonal directions, and two real-time control currents are obtained, respectively, according to the displacement of the rotor to generate the electromagnetic force for suppressing the rotor imbalance vibration. Finally, the feasibility of this algorithm on an unbalanced vibration suppression is verified by experiments at different rotating speeds.

\section{MODELING AND ANALYSIS OF TEST RIG}

\subsection{Description of Test Rig}

The test rig of the rotor-bearing AMA system is shown in Fig. 1. The main components included a rotor, disk, tilting pad bearing, AMA, sensor, data acquisition system, control system, and drive system. The length of the rotor was $876 \mathrm{~mm}$, the outer diameter was $50 \mathrm{~mm}$, the material was $40 \mathrm{Gr}$, and both ends were supported by the tilting pad bearing and were driven by an electric spindle through the coupling. The diameter of the disc was $270 \mathrm{~mm}$, the thickness was $25 \mathrm{~mm}$, and its material was 45 steels. The AMA consisted of a stator and rotor; the stator consisted of 12 poles. The energy loss and coupling 


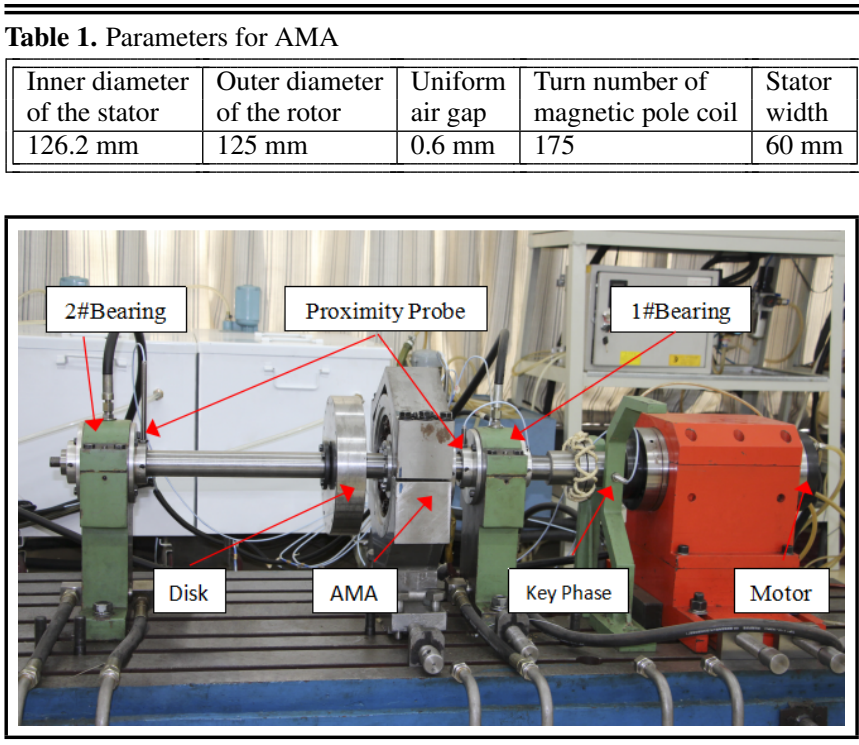

Figure 1. Test rig of rotor-bearing AMA system.

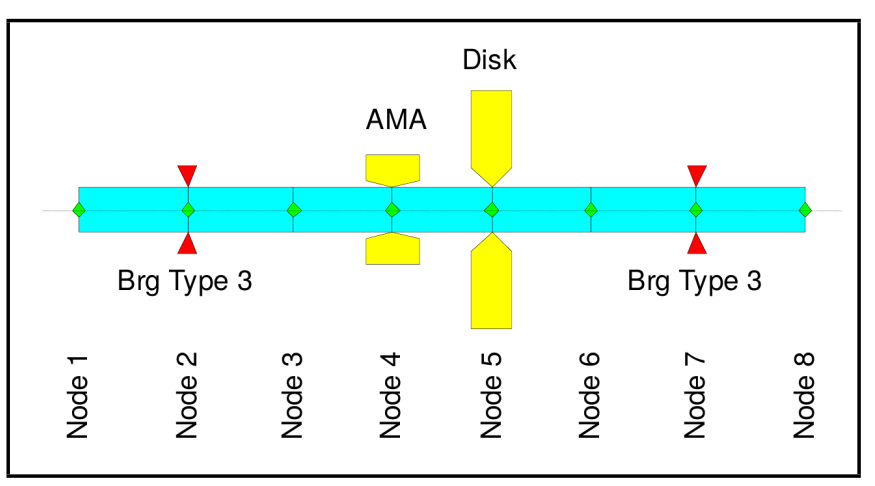

Figure 2. Model of rotor-bearing AMA system.

of the 12-magnetic pole structure were less; the other parameters of the AMA are shown in Table 1. A key-phase sensor was located at the coupling to measure the speed. Eddy current displacement sensors were arranged at the two ends of the bearing and the electromagnetic device, respectively, to measure the vibration displacement of the rotor.

\subsection{Model of Rotor in Test Rig}

The finite element model of rotor-bearing system was established, as shown in Fig 2. Units that built the model included disks, shaft segments, bearings, and the AMA.

The equation of motion for the rotor-bearing AMA system was: ${ }^{8}$

$$
[M][\ddot{Z}]+[C][\dot{Z}]+[K][Z]=[Q]
$$

where:

$$
\begin{aligned}
{[M] } & =\sum\left[M_{d}\right]+\sum\left[M_{S}\right] ; \\
{[C] } & =\sum \Omega\left[G_{S}\right]+\sum \Omega\left[G_{d}\right]+\sum\left[C_{b}\right] ; \\
{[K] } & =\sum\left[K_{S}\right]+\sum\left[K_{d}\right]+\sum\left[K_{b}\right] ; \\
{[Q] } & =\sum\left[Q_{S}\right]+\sum\left[Q_{d}\right]+\sum\left[Q_{m a g}\right]
\end{aligned}
$$

The set $[Z]$ was the displacement vector, $[M]$ was the mass matrix, $\left[M_{d}\right]$ was the mass matrix of the disk element in the global coordinate system, and $\left[M_{s}\right]$ was the mass matrix of the shaft section element in the global coordinate system. The set
$[C]$ was the system damping matrix, $\left[G_{s}\right]$ was the gyro matrix of the axial section element in the global coordinate system, $\left[G_{d}\right]$ was the gyro matrix of the disk element in the global coordinate system, $\left[G_{b}\right]$ was the damping matrix of the bearing element in the global coordinate system, and $\Omega$ was speed. The set $[K]$ was the system stiffness matrix, $\left[K_{s}\right]$ was the stiffness matrix of the shaft element in the global coordinate system, $\left[K_{d}\right]$ was the stiffness matrix of the disk element in the global coordinate system, and $\left[K_{b}\right]$ was the stiffness matrix of the bearing element in the global coordinate system. The set $[Q]$ was the generalized force of a system, $\left[Q_{s}\right]$ was the generalized force of the shaft element, $\left[Q_{d}\right]$ was the generalized force of the disk element, and $\left[Q_{\text {mag }}\right]$ was the external control force. If the unbalance force was caused by the eccentric shaft section, regardless of quality and other exciting force, only considering the unbalance force was caused by the disc mass eccentricity and the external electromagnetic force, then: ${ }^{8}$

$$
[Q]=\sum\left[Q_{d}\right]+\sum\left[Q_{m a g}\right]
$$

In the local coordinate system, it was assumed that the eccentric distance of the disk was $e$, and the phase angle of the mass eccentricity was $\gamma$, the mass of the disc was $m_{d}$. Then the node unbalanced force of disc was expressed as: ${ }^{6}$

$$
\left[Q_{d}^{e}\right]=m_{d} \Omega^{2} e\left[\begin{array}{c}
\cos (\Omega t+\gamma) \\
\sin (\Omega t+\gamma)
\end{array}\right] .
$$

Equation (3) was transformed into a global coordinate system by using the transformation matrix $\left[T_{d}^{T}\right]$.

$$
\left[Q_{d}\right]=\left[T_{d}^{T}\right]+\sum\left[Q_{d}^{e}\right]
$$

The electromagnetic force in the direction of $X$ was obtained from the Maxwell electromagnetic field theory as follows: 4

$$
f_{\text {mag }}^{x}=k \frac{i_{x}^{2}}{x^{2}}, \quad k=\frac{\mu_{0} N^{2} A}{4} ;
$$

where $\mu_{0}$ was space permeability, $N$ was the number of field turns, $A$ was the pole area, $x$ was the air gap, and $i_{x}$ was the current. The Taylor expansion was carried out near $x=0$ and $i_{x}=0$, and the higher order infinitesimal was neglected. The linearized expression near the work point could be obtained. $I_{0}$ was the bias current, and $\delta_{0}$ was the static air gap. ${ }^{4}$

$$
f_{\text {mag }}^{x}=-k_{s} x+k_{i} i_{x}
$$

Here, $k_{x}=\mu_{0} N^{2} A I_{0}^{2} / \delta_{0}^{3}$ was the displacement stiffness, and $k_{i}=\mu_{0} N^{2} A I_{0} / \delta_{0}^{2}$ was the current stiffness.

Assume that the air gap and the magnetic pole in the horizontal $(X)$ and vertical $(Y)$ directions were uniform, and the magnetic field coupling between the $X$ and the $Y$ directions was not considered. It could be considered that the current stiffness and displacement stiffness are equal in both directions, respectively.

$$
\begin{aligned}
{\left[Q_{\text {mag }}^{e}\right]=} & {\left[\begin{array}{ll}
f_{\text {mag }}^{x} & f_{m a g}^{y}
\end{array}\right]^{T}=} \\
& -k_{s}\left[\begin{array}{l}
x \\
y
\end{array}\right]+k_{i}\left[\begin{array}{c}
i_{x} \\
i_{y}
\end{array}\right]=-k_{s}\left[z_{a}\right]+k_{i}\left[I_{a}\right]
\end{aligned}
$$

It was necessary to transform the electromagnetic force and the local displacement into the displacement and control force 
in the global coordinate system by the transformation matrix $\left[T_{a}\right]$, so that the above equations could be a unified treatment. ${ }^{27}$

$$
\left[Q_{\text {mag }}\right]=\left[T_{a}^{T}\right]\left\{-k_{s}\left[T_{a}\right]\left[z_{a}\right]+k_{i}\left[I_{a}\right]\right\}
$$

When considering the system contains only a single disc, then the equations of motion was:

$$
[M][\ddot{Z}]+[C][\dot{Z}]+[K][Z]=\left[Q_{d}\right]+\left[Q_{m a g}\right] .
$$

Substituting Eq. (8) into Eq. (9):

$$
\begin{array}{r}
{[M][\ddot{Z}]+[C][\dot{Z}]+\left\{[K]+k_{s}\left[T_{a}^{T}\right]\left[T_{a}\right]\right\}[Z]=} \\
{\left[Q_{d}\right]+k_{i}\left[T_{a}^{T}\right]\left[I_{a}\right] .}
\end{array}
$$

On the right of the above equation, the size of the second term depended on the actuator coil current $\left[I_{a}\right]$, which could be used for vibration control of the rotor system. Set a new stiffness matrix $\left[K_{1}\right]$ as:

$$
\left[K_{1}\right]=[K]+k_{s}\left[T_{a}^{T}\right]\left[T_{a}\right] .
$$

\section{PD FEEDBACK BASED CONTROL STRATEGY}

\subsection{State Space Description}

When the rotor is considered as a flexible rotor, the system dynamics equation established by the finite element method will include multiple state variables. When analysing multiple input multiple output control structures (MIMO), the state space description method was very useful. Therefore, the equations of motion needed to be transformed. First, the state space vector was defined: ${ }^{27}$

$$
[q]=\left[\begin{array}{c}
Z \\
\dot{Z}
\end{array}\right], \quad[\dot{q}]=\left[\begin{array}{c}
\dot{Z} \\
\ddot{Z}
\end{array}\right] .
$$

The $[\ddot{Z}]$ was represented by Eq. (10) as: ${ }^{27}$

$$
\begin{aligned}
{[\ddot{Z}]=[M]^{-1} } & {\left[Q_{d}\right]+[M]^{-1}\left\{k_{i}\left[T_{a}^{T}\right]\left[I_{a}\right]\right\} } \\
& -[M]^{-1}[C][\dot{Z}]+-[M]^{-1}\left[K_{1}\right][Z] .
\end{aligned}
$$

Converted the above equation to a first order expression: ${ }^{27}$

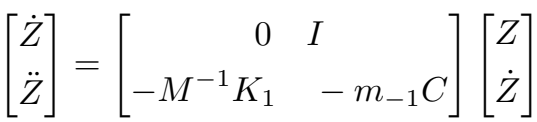

$$
\begin{aligned}
& +\left[\begin{array}{c}
0 \\
M^{-1}
\end{array}\right]\left[Q_{d}\right]+\left[\begin{array}{c}
0 \\
M^{-1}
\end{array}\right] k_{i}\left[T_{a}^{T}\right]\left[I_{a}\right] .
\end{aligned}
$$

Simplified Eq. (14) as:

$$
[\dot{q}]=\left[A_{s}\right][q]+\left[B_{s a}\right]\left[I_{a}\right]+\left[B_{s u}\right]\left[Q_{d}\right] ;
$$

where $\left[A_{s}\right],\left[B_{s a}\right]$, and $\left[B_{s u}\right]$ were the system matrix, input matrix of the AMA current and the unbalanced force, respectively. As the second state space equations, the output relationship was defined. The set $\left[Z_{c}\right]$ was the displacement vector of the measured point.

$$
\left[Z_{c}\right]=\left[\begin{array}{ll}
T_{s} & 0
\end{array}\right]\left[\begin{array}{c}
q \\
\dot{q}
\end{array}\right] .
$$

\subsection{PD Feedback Algorithm}

The PD feedback control strategy of vibration displacement was adopted to generate the electromagnetic force of the AMA. According to Eq. (3), the unbalance force was decomposed into two directions of $X$ and $Y$. The corresponding control forces were also applied in two orthogonal directions, respectively. According to the equation of state feedback displacement vector $\left[Z_{c}\right]$, the PD control algorithm for feedback control was chosen. The deviation signal was formed by the difference between the given value $z_{d}(t)$ and the actual output value $z(t)$ :

$$
e(t)=z_{d}(t)-z(t) .
$$

The control law of the PD was:

$$
u(t)=k_{p}\left[e(t)+\frac{T_{D} d e(t)}{d t}\right] ;
$$

where $k_{p}$ was the proportional coefficient and $T_{D}$ was the differential time constant.

With a series of sampling time points, $k_{T}$ represented the continuous time $t$ and first-order backward difference, which replaced the differential approximately, that is:

$$
\left\{\begin{array}{c}
t \approx k T \quad(k=0,1,2, \ldots) \\
\frac{d e(t)}{d t} \approx \frac{e(k T)-e((k-1) T)}{T}=\frac{e(k)-e(k-1)}{T} .
\end{array}\right.
$$

The discrete PD expression was obtained by substituting Eq. (19) into Eq. (18):

$$
u_{k}=k_{p} e(k)+k_{d} \frac{e(k)-e(k-1)}{T}
$$

where $k_{d}=k_{p} T_{D}, T$ was the sampling period, $k$ was the sampling number, and $e(k)$ and $e(k-1)$ were the deviation signals, respectively, that were obtained at the $k$ moment and the $(k-1)$ moment.

The block diagram of the control system is shown in Fig. 3. The $Y$ direction and the $X$ direction were the same in principle.

The displacement vector at the $\mathrm{k}$-th sampling time of the node where the AMA was located was $\left[Z_{c}(k)\right]=$ $\left[z_{x}(k) \quad z_{y}(k)\right]$. The deviations in the $X$ and $Y$ directions were $e_{x}(k)=z_{d}-z_{x}(k)$ and $e_{y}(k)=z_{d}-z_{y}(k)$, respectively. According to Eq. (20), the control signal $[U]$ was obtained as follows:

$$
[U]=\left[\begin{array}{l}
u_{x} \\
u_{y}
\end{array}\right]=\left[\begin{array}{l}
k_{p} e_{x}(k)+k_{d} \frac{e_{x}(k)-e_{x}(k-1)}{T} \\
k_{p} e_{y}(k)+k_{d} \frac{e_{y}(k)-e_{y}(k-1)}{T}
\end{array}\right] .
$$

Therefore, Eq. (15) became:

$$
[\dot{q}]=\left[A_{s}\right][q]+\left[B_{s a}\right][U]+\left[B_{s u}\right]\left[Q_{d}\right] .
$$

According to Eq. (22), the essence of the AMA was to adjust the magnitude of the control current according to the deviation signal of the rotor vibration displacement. By weakening or offsetting the influence of the right third items of the upper formula to achieve the purpose of changing the stiffness and damping of the rotor system, then the vibration response reduction of the unbalanced rotor was realized. 


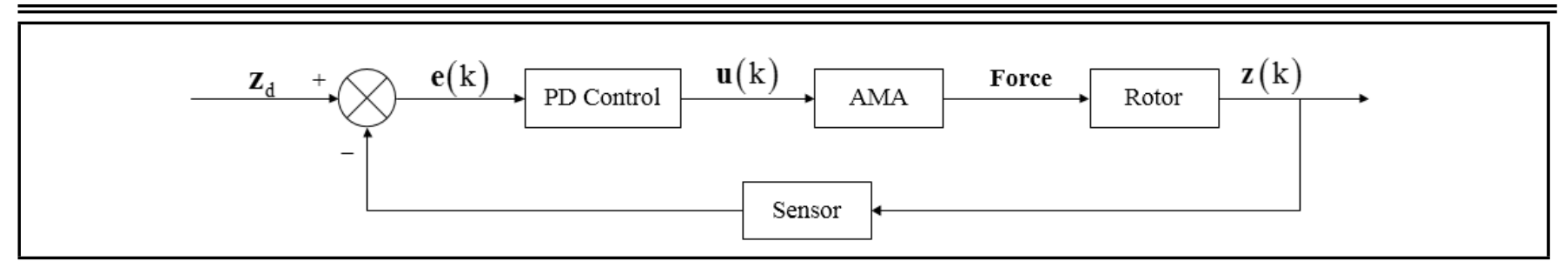

Figure 3. PD control strategy of rotor vibration due to unbalance in rotor-bearings system.

\section{NUMERICAL SIMULATION}

A numerical simulation has been developed for evaluating the effectiveness of the PD feedback-based control method. The model of the rotor-bearing AMA system is shown in Fig. 2.

The working speeds were set at 2000, 4000 and $6000 \mathrm{r} / \mathrm{min}$, respectively. The initial state was set to 0 . The values of the proportional coefficient $\mathrm{kp}$ and the differential coefficient $k_{d}$ were selected by trial and error. The general principle was to firstly select an appropriate $k_{p}$ value without considering the $k_{d}$, and then to perform the debugging of the $\mathrm{k} d$ value. Finally, the $k_{p}$ was taken as $10^{9}$ and $k_{d}$ was taken as $10^{5}$. The control was applied after 0.2 seconds of the program running. The vibration displacements in the $X$ (horizontal) and $Y$ (vertical) directions of the node where the AMA was located and the node 3 which near the left bearing are shown in Fig. 4, Fig. 5, and Fig. 6. The effect of the PD control on an unbalanced vibration at different rotational speeds was analysed.

The simulation results have shown that the real-time control algorithm based on the PD feedback proposed in this paper have a good effect on the vibration response suppression of the unbalanced rotor, which could effectively reduce the amplitude of rotor vibration, adjust quickly, and there should be no overshoot. The algorithm was simple, and the parameters were clear. The controller generated a real-time control current to act on the AMA according to the real-time displacement of the rotor vibration. Then, the AMA generated an electromagnetic force to control the rotor vibration. It can be seen from Fig. 4 to Fig. 6 that a significant suppression effect was obvious for three different rotational speeds, using the AMA based on the PD control algorithm. The PD parameters can be adjusted according to the actual working conditions.

\section{EXPERIMENTAL VERIFICATION}

The effect of the algorithm on the suppression of the unbalanced vibration is experimentally verified at the test rig shown in Fig. 1. The real-time suppression of the unbalanced vibration of the rotor at speeds of $1200 \mathrm{r} / \mathrm{min}, 1500 \mathrm{r} / \mathrm{min}$, $1800 \mathrm{r} / \mathrm{min}, 2100 \mathrm{r} / \mathrm{min}$, and $2400 \mathrm{r} / \mathrm{min}$, respectively, was carried out. The eddy current displacement sensors were arranged in the horizontal and vertical directions, respectively, and collected the real-time vibration amplitudes of the rotor in two directions and transmitted them to the controller for calculation. The effect of unbalanced rotor vibration reduction at the speed of $1500 \mathrm{r} / \mathrm{min}$ is shown in Fig. 7. The whole process was divided into two stages, before and after the application of the control. The effect comparisons at 1200, 1500, 1800, 2100, and $2400 \mathrm{r} / \mathrm{min}$ are shown in Fig. 8.

From the experimental results, some conclusions can be drawn. In the rotor-bearing AMA system, there was a significant suppression effect, when the PD control algorithm was used to suppress the unbalanced vibration of the rotor in real time. The proposed algorithm is slightly different in suppressing the horizontal and vertical unbalanced vibrations because the stiffness and damping of the bearing are not the same in the horizontal and vertical direction. Though unbalanced vibration tends to increase with the increase of rotational speed, the algorithm of this paper still maintains a good effect of suppressing unbalanced vibration under different rotational speeds.

\section{CONCLUSIONS}

The finite element model of the rotor-bearing AMA is established and transformed into the expression in the state space in this paper. An active control method based on the proportionalderivative feedback-control strategy is proposed. Through the combination of simulation and experiment, the real-time suppression of the rotor unbalance vibration at different rotational speeds is carried out. The inhibitory effect of the PD algorithm based on the AMA actuator on the unbalanced rotor vibration at different speeds is verified. However, there is a residual error for the PD feedback-based control algorithm, in which the vibration response of the unbalanced rotor cannot be eliminated completely. The control algorithm needs to be further optimized for higher requirements of balance accuracy.

\section{AKNOWLEDGEMENTS}

The research was supported by Beijing Natural Science Foundation (3132025) and the Fundamental Research Funds for the Central Universities (JD1713).

\section{REFERENCES}

1 Liu, J., Liu, Z., Chen, J., and Wang, L. Research of vibration control on nonlinear rotor system with Fuzzy-PID, Journal of System Simulation, 29 (1), 200-205, (2017). https://dx.doi.org/10.16182/j.issn1004731x.joss.201701026

2 Song, J., Ou Yang, H., and Zhang, G. Research on dynamics analysis and active vibration control of magnetic bearing rotor, Mechanical and Electrical Engineering Technology, 43 (12), 166-167, (2014). http://dx.chinadoi.cn/10.3969/j.issn.10099492.2014.12.042

3 Wang, H. Survey of the research on active vibration control of flexible rotor, Machine Building and Automation, 40 (5), 1-5, (2011). http://dx.chinadoi.cn/10.3969/j.issn.16715276.2011.05.001

4 Das, A. S., Nighil M. C., Dutt, J. K., and Irretier, H. Vibration control and stability analysis of rotorshaft system with electromagnetic exciters, Mechanism and Machine Theory, 43 (10), 1295-1316, (2008). https://dx.doi.org/10.1016/j.mechmachtheory.2007.10.007

5 Das, A. S., Dutt, J. K., and Ray, K. Active control of coupled flexural-torsional vibration in a flexible rotor-bearing system using electromagnetic actuator, Int. 


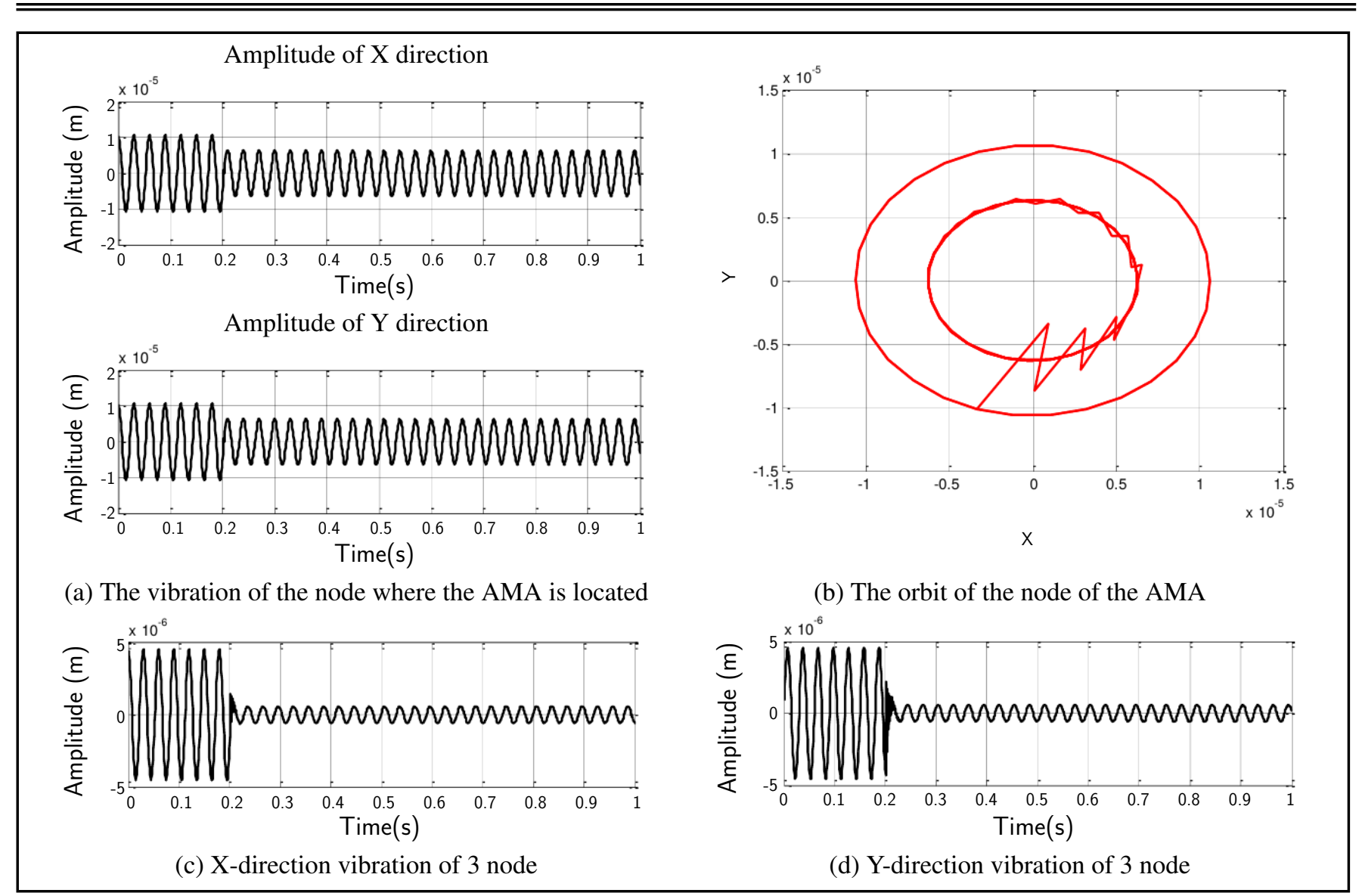

Figure 4. Rotor vibration simulation results at rotational speed $\Omega=2000 \mathrm{r} / \mathrm{min}$ with and without control.

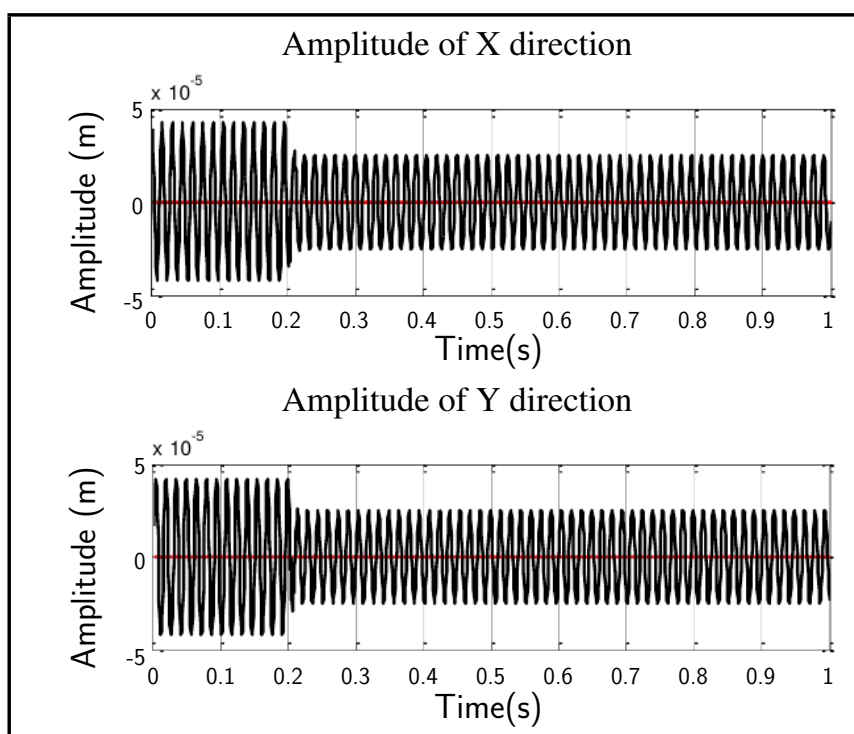

(a) The vibration of the node where the AMA is located

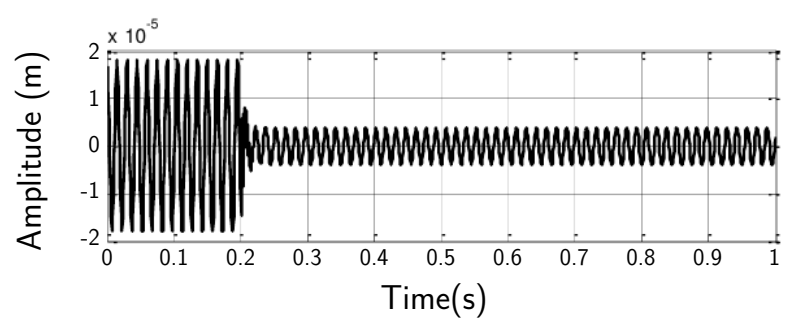

(c) X-direction vibration of 3 node

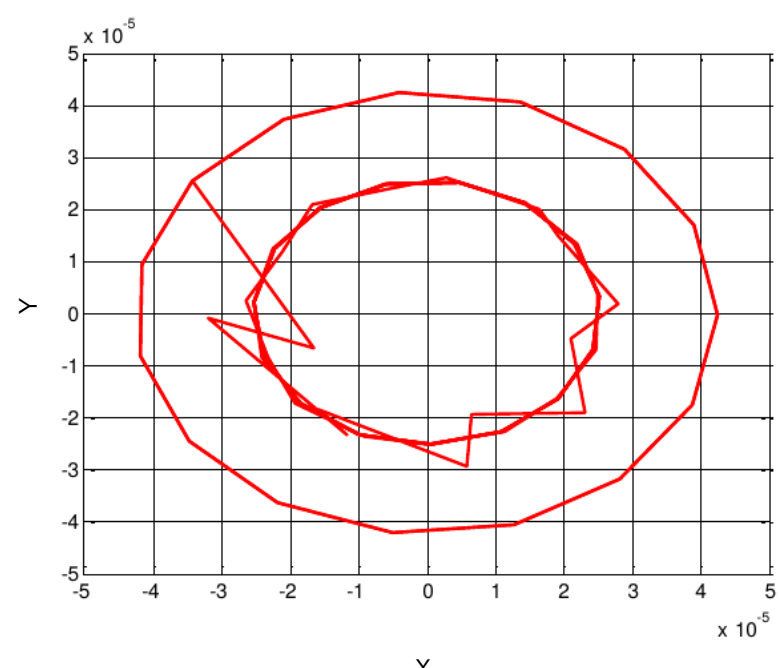

(b) The orbit of the node of the AMA

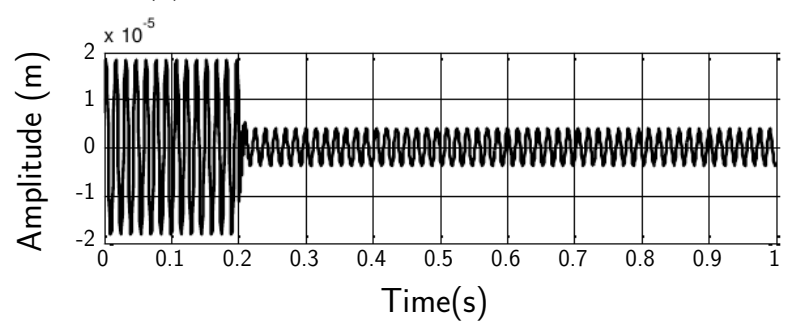

(d) Y-direction vibration of 3 node

Figure 5. Rotor vibration simulation results at rotational speed $\Omega=4000 \mathrm{r} / \mathrm{min}$ with and without control. 


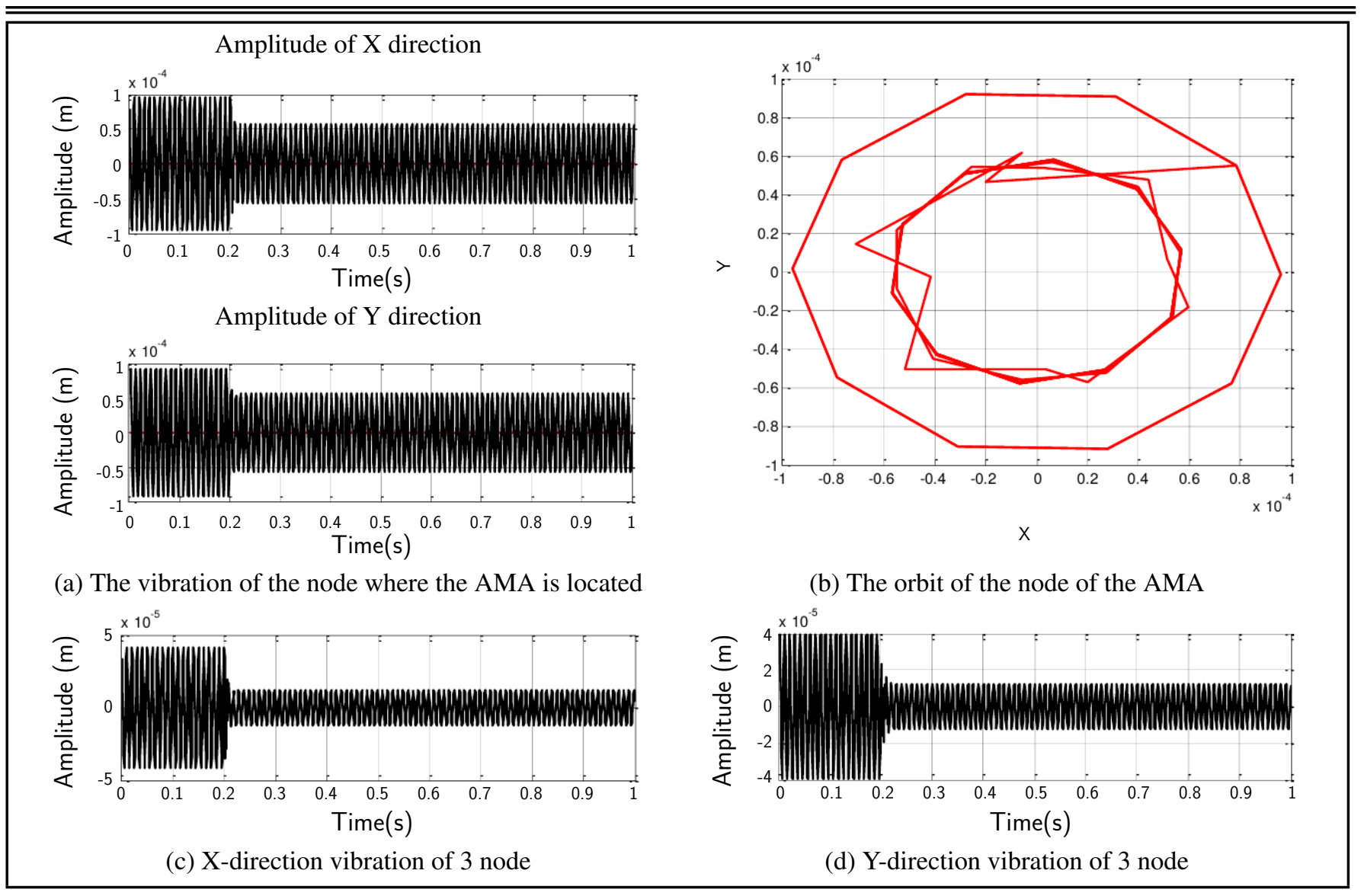

Figure 6. Rotor vibration simulation results at rotational speed $\Omega=6000 \mathrm{r} / \mathrm{min}$ with and without control.

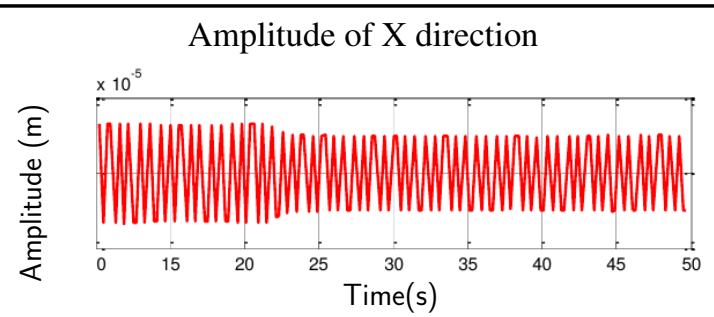

(a) Horizontal direction of $1 \#$ bearing Amplitude of $\mathrm{X}$ direction

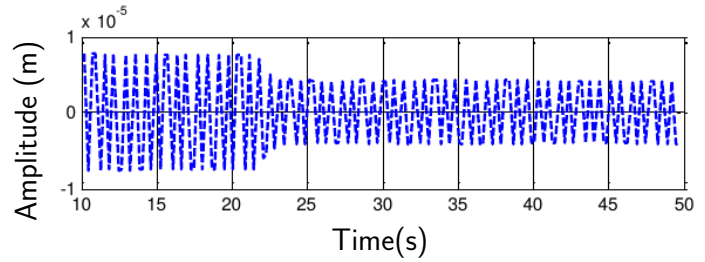

(c) Horizontal direction of $2 \#$ bearing

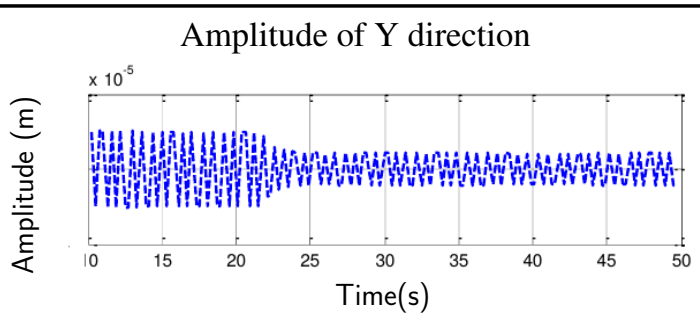

(b) Vertical direction of $1 \#$ bearing Amplitude of Y direction

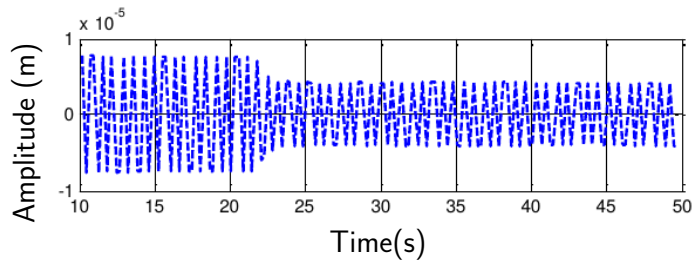

(d) Vertical direction of $2 \#$ bearing

Figure 7. Rotor vibration reduction experimental results at rotational speed $\Omega=1500 \mathrm{r} / \mathrm{min}$.

J. Non-Linear Mechanics, 46 (9), 1093-1109, (2011). https://dx.doi.org/10.1016/j.ijnonlinmec.2011.03.005

6 Fan, C., and Pan, M. Active elimination of oil and dry whips in a rotating machine with an electromagnetic actuator, Int. J. Mechanical Sciences, 53 (2), 126-134, (2011). https://dx.doi.org/10.1016/j.ijmecsci.2010.12.002

7 Saeed, N. A., and Kamel, M. Nonlinear PDcontroller to suppress the nonlinear oscillations of horizontally supported Jeffcott-rotor system, Int. J. Non-Linear Mechanics, 87, 109-124, (2016). https://dx.doi.org/10.1016/j.ijnonlinmec.2016.10.003
8 Yao, J., Gao, J., and Wang, W. Multi-frequency rotor vibration suppressing through self-optimizing control of electromagnetic force, J. Vib. Control, 23 (5), 701-715, (2017). https://dx.doi.org/10.1177/1077546315586301

9 Chen, Q., Liu, G., and Zheng, S. Suppression of imbalance vibration for AMBs controlled driveline system using double-loop structure, J. Sound Vib., 337, 1-13, (2015). https://dx.doi.org/10.1016/j.jsv.2014.09.042

10 Chen, S., and Lin, F. Decentralized PID neural network control for five degree-of-freedom active magnetic bearing, Engineering Applications 


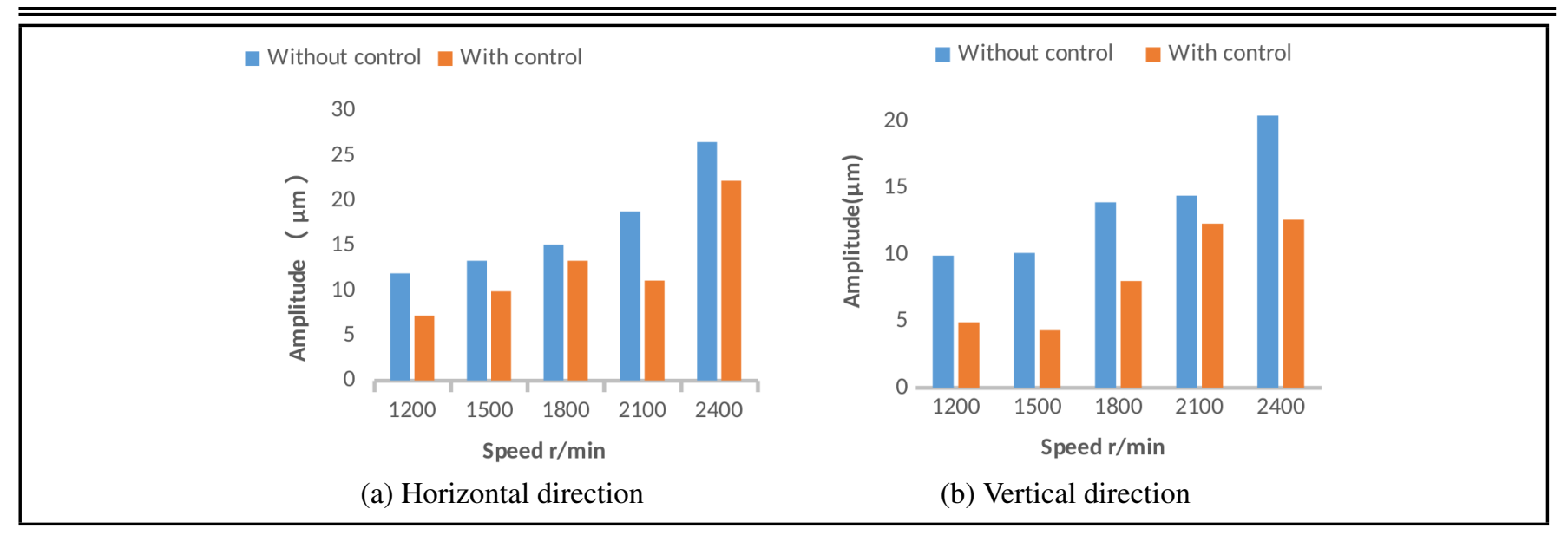

Figure 8. Rotor vibration magnitude with and without control of different rotational speed.

of Artificial Intelligence, 26 (3), 962-973, (2013). https://dx.doi.org/10.1016/j.engappai.2012.11.002

11 Heydari, A., Mirpariz, M., Shakeriaski, F., Samani, F. S., and Keshavarzi, M. Nonlinear vibration analysis of a rotor supported by magnetic bearings using homotopy perturbation method, Propulsion and Power Research, 6 (3), 223232, (2017). https://dx.doi.org/10.1016/j.jppr.2017.07.004

12 Jiang, K., and Zhu, C. Vibration suppressing with mixed weight for multi-targets in active magnetic bearing - flexible rotor system, J. Zhejiang University, 50 (10), 19461951, (2016). http://dx.chinadoi.cn/10.3785/j.issn.1008973X.2016.10.014

13 Wang, J., and Zeng, L. Synchronous suspension control study for magnetic bearing rotor displacement, Modern Manufacturing Engineering, 8, 1216, (2011). http://dx.chinadoi.cn/10.3969/j.issn.16713133.2011.08.003

14 Kumar, G., Choudhury, M. D., Natesan, S., and Kalita, K. Design and analysis of a radial active magnetic bearing for vibration vontrol, Procedia Engineering, 144, 810-816, (2016). https://dx.doi.org/10.1016/j.proeng.2016.05.090

15 Roy, H. K., Das, A. S., and Dutt, J. K. An efficient rotor suspension with active magnetic bearings having viscoelastic control law, Mechanism and Machine Theory, 98, 48-63, (2016). https://dx.doi.org/10.1016/j.mechmachtheory.2015.11.012

16 Kandil, M. S., Dubois, M. R., Bakay, L. S., and Trovao, J. F. Application of second-order sliding-mode concepts to active magnetic bearingsp, IEEE Transactions on Industrial Electronics, 65 (1), 855-864, (2018). https://dx.doi.org/10.1109/tie.2017.2721879

17 Zheng, S., and Feng, R. Feedforward compensation control of rotor imbalance for high-speed magnetically suspended centrifugal compressors using a novel adaptive notch filter, J. Sound Vib., 366, 1-14, (2016). https://dx.doi.org/10.1016/j.jsv.2015.12.029

18 Cui, P., Ge, Y., Fang, J., and Li, H. Adaptive control for unbalance vibration ofa ctive-passive hybrid magnetically suspended rotor, Optics and Precision Engineering, 23 (1), 122-130, (2015). https://dx.doi.org/10.3788/OPE.20152301.0122

19 Tang, E., Fang, J., and Zheng, S. Vibration control and experimental study of flexible rotor in magnetically sus- pended motor, J. Mechanical Engineering, 51 (1), 106-116, (2015). https://dx.doi.org/10.3901/jme.2015.01.106

20 Mao, C., and Zhu, C. Unbalance compensation for active magnetic bearing rotor system using a variable step size real-time iterative seeking algorithm, IEEE Transactions on Industrial Electronics, 65 (5), 4177-4186, (2018). https://dx.doi.org/10.1109/tie.2017.2772144

21 Zhao, J., Zhang, H., Fan, M, Wu, Y., and Zhao, H. Control of a constrained flexible rotor on active magnetic bearings, IFAC-Papers OnLine, 48 (28), 156-161, (2015). https://dx.doi.org/10.1016/j.ifacol.2015.12.117

22 Gürleyen, F. Model Based Robust Stabilizing Adaptive Variable Structure Control (RSAVSC) for MAGLEV and Active Magnetic Bearings, IFAC Proceedings Volumes, 46 (25), 133-138, (2013). https://dx.doi.org/10.3182/20130916-2-tr-4042.00040

23 Sun, X., Su, B., Chen, L., Yang, Z., Xu, X., and Shi, Z. Precise control of a four degree-of-freedom permanent magnet biased active magnetic bearing system in a magnetically suspended direct-driven spindle using neural network inverse scheme, Mechanical Systems and Signal Processing, 88, 36-48, (2017). https://dx.doi.org/10.1016/j.ymssp.2016.11.022

24 Saeed, N. A., and Kamel, M. Active magnetic bearingbased tuned controller to suppress lateral vibrations of a nonlinear Jeffcott rotor system, Nonlinear Dyn., 90 (1), 457-478, (2017). https://dx.doi.org/10.1007/s11071-0173675-y

25 Yoon, S., Di, L., and Lin, Z. Unbalance compensation for AMB systems with input delay: An output regulation approach, Control Engineering Practice, 46 (4), 166-175, (2016). https://dx.doi.org/10.1016/j.conengprac.2015.11.002

26 Mitenkov, F. M., Ovchinnikov, V. F., Nikolaev, M. Y., and Litvinov, V. N. Synthesis of Control System and Control Algorithm for Compensating for the Residual Imbalance of a Complex Flexible Rotor on Electromagnetic Suspension, J. Machinery Manufacture and Reliability, 46 (4), 409-413, (2017). https://dx.doi.org/10.3103/s1052618817040112

27 Eric, H. M., and Gerhard, S. Magnetic bearings: theory, design, and application to rotating machinery, Springer-Verlag Berlin Heidelberg, New York, (2009). https://dx.doi.org/10.1007/978-3-642-00497-1 